\title{
Vibratory Membrane Separation for Wastewater Treatment
}

\author{
PÉTER BOR ${ }^{1}$, JÓZSEF CSANÁdI ${ }^{2}$, GÁbOR VERÉB ${ }^{1}$, SÁNDOR BESZÉDES1, \\ ZITA Šereš ${ }^{3}$, ZSUZSANNA LÁSZLÓ ${ }^{1}$, CECILIA HODÚR ${ }^{1,4}$, \\ SZABOLCS KERTÉSZ ${ }^{*}$ *
}

\begin{abstract}
To meet the requirements defined by environmental protection regulations effective wastewater treatment is required to process effluents before discharging them into sewers or living waters. While membrane separation offers a quite advantageous method to reduce the organic load of wastewaters, membrane fouling is still limiting its application in wastewater treatment.

In this study, the possibility of membrane fouling reduction by increased shear rates on the surface of the membrane was investigated. 7 and $10 \mathrm{kDa} M W C O$ ultrafiltration and $240 \mathrm{Da}$ nanofiltration membranes were studied, with the use of a laboratory mode Vibratory Shear Enhanced Processing. This work mostly focused on studying the effects of module vibration and recirculation feed flow rate on permeate flux, specific energy demand and membrane rejections. Using the same operation parameters, vibration and non-vibration mode experiments were carried out with high and low recirculation flow rate to have a deeper understanding of the shear rate effects. It can be concluded that higher shear rate had a positive effect on the process: increased shear rate resulted in higher flux, higher overall rejection values, as well as a significantly decreased specific energy demand. By calculating and comparing the shear rates in experiments with different operating parameters, both vibration and nonvibration mode, both low and high recirculation flow rate, we have reached the conclusion that vibration causes a significantly higher shear rate increase than setting the recirculation flow rate high.
\end{abstract}

Keywords: vibratory membrane separation, dairy wastewater, ultrafiltration, nanofiltration, fouling, shear rate, vibration

* Corresponding author. E-mail: kertesz@mk.u-szeged.hu

1 Department of Process Engineering, Faculty of Engineering, University of Szeged, Moszkvai krt. 9., H-6725 Szeged, Hungary

2 Department of Food Engineering, Faculty of Engineering, University of Szeged, Moszkvai krt. 5-7., H-6725 Szeged, Hungary

${ }^{3}$ Faculty of Technology, University of Novi Sad, Bul. Cara Lazara 1, 21000 Novi Sad, Serbia

4 Institute of Environmental Sciences and Technology, University of Szeged, Tisza Lajos krt. 103., H-6720 Szeged, Hungary 


\section{Introduction}

The European Union is constantly making serious efforts to address environmental issues, mainly by restricting the protection regulations. Food industry - including dairy industry - uses a huge amount of water for its processes, resulting in vast amounts of effluents. Generally, these effluents can be characterized by high organic load, going along with high chemical oxygen demand $(C O D)$ and biological oxygen demand $(B O D)$. Regulations concerning wastewater disposal require the effective decrease of these pollutants until they meet certain criteria (Rezvantalab et al., 2015). In addition to the conventional wastewater treatment technologies, membrane separation is a good means to reduce both organic and inorganic load of dairy effluents (Luján-Facundo et al., 2017; Frappart et al., 2008). An important advantage of membrane separation is the low amount of chemicals required by the process, while the technology can run on mild operation parameters, and it is easily combinable with other technologies (Molina et al., 2008; Limsawat et al., 2010). Unfortunately, membrane separation has some drawbacks. Both the efficacy and the feasibility of the technology is limited by membrane fouling caused by pore blocking or concentration polarization, leading to flux decline (Bian et al., 2000; Takács et al., 2006). Numerous researches have been addressing this issue, by increasing the shear rates present on the surface of the membrane. In some studies, researchers have managed to increase shear rates by using a static promoter (Koris et al., 2011; Schroen et al., 2017). Others were experimenting with different mechanical methods, to increase shear rates for example by rotating or vibrating the membrane module (Zhenzhou et al., 2016; Goh et al., 2018). Jianquan et al. claimed that by increasing shear rates, one can reduce pore blocking, thus increase flux (Jianquan et al., 2012). In this study, the feasibility of Vibratory Shear Enhanced Processing (VSEP) was investigated in dairy wastewater treatment, by processing model dairy effluent with a laboratory mode VSEP, equipped with ultrafiltration (UF) and nanofiltration (NF) membranes. Shear rates caused by recirculation flow rate $(R F R)$ and vibration were calculated and compared. The impact of shear rates (in both low and high $R F R$, and in both vibrated and non-vibrated modes) on flux, specific energy demand and rejection values were analyzed and compared. 


\section{Materials and methods}

\subsection{Model dairy wastewater}

Model dairy wastewater was used as feed in the experiments, which was prepared from distilled water and contained skim milk powder (MilkQuick, Hungary) in a concentration of $5 \mathrm{~g} / \mathrm{dm}^{3}$ and CL 80 anionic detergent (HungaroChemicals, Nagycserkesz) in a concentration of $0.5 \mathrm{~g} / \mathrm{dm}^{3}$. Characteristics of this dairy wastewater were measured at $50^{\circ} \mathrm{C}$ and are shown in Table 1.

Table 1. Model dairy wastewater characteristics at $50^{\circ} \mathrm{C}$

\begin{tabular}{|c|c|c|c|c|c|c|c|c|}
\hline $\begin{array}{c}\text { Cemical } \\
\text { oxygen } \\
\text { demand }\end{array}$ & $\begin{array}{c}\text { Electric } \\
\text { conductiv } \\
\text { ity }\end{array}$ & $\mathrm{ph}$ & Turbidity & Denisity & Protein & $\begin{array}{c}\text { Dry } \\
\text { matter }\end{array}$ & Lactose & Viscosity \\
\hline$\left[\mathrm{mgL}^{-1}\right]$ & {$\left[\mu \mathrm{Sm}^{-1}\right]$} & {$[-]$} & {$[\mathrm{NTU}]$} & {$\left[\mathrm{kgm}^{-3}\right]$} & {$[\mathrm{g} / \mathrm{g}]$} & {$[\mathrm{g} / \mathrm{g}]$} & {$[\mathrm{g} / \mathrm{g}]$} & {$[\mathrm{mPas}]$} \\
\hline 5000 & 1300 & 7.25 & 330 & 953.9 & 0.32 & 0.102 & 0.233 & 0.37 \\
\hline
\end{tabular}

\subsection{Analytical methods}

Chemical oxygen demands of the samples were determined with ET 108 digester and a PC CheckIt photometer (Lovibond, Germany). The digestion was done at $150{ }^{\circ} \mathrm{C}$ for 2 hours, as the European protocol requires. Turbidity was measured with a HACH 2100AN turbidimeter (Hach, Germany). Density measurements were done with a Mettler Toledo 30PX Densito (Mettler-Toledo, Switzerland) portable density meter. Lactose, protein, and dry matter content of the samples were analyzed with a Bentley 150 infrared milk analyzer (Bentley Instruments, USA). Electric conductivity and $\mathrm{pH}$ were determined with a BVBA C5010 multimeter (Consort, Belgium). Viscosity was given by an A\&D vibro viscometer SV10 (A\&D, Japan). All the analytic measurements were done at least three times, and the results were averaged.

\subsection{Membranes and VSEP operating parameters}

VSEP Series LP filtration apparatus (New Logic Research Inc., USA) equipped with an $L$ (Laboratory) module was used. Inside the module, a single circular membrane was inserted, with an effective membrane area of $503 \mathrm{~cm}^{2}$, inner radius $\left(R_{1}\right)$ of $4.7 \mathrm{~cm}$ and outer radius $\left(R_{2}\right)$ of $13.5 \mathrm{~cm}$. Two polyethersulfone (PES) UF membranes were used, one with a molecular 
weight cut off (MWCO) of 10 kDa (PES-10 SYN, New Logic Research Inc., USA) and one with $7 \mathrm{kDa}$ (PES-5/Tyvek, New Logic Research Inc., USA). Furthermore, a thin film composite NF membrane with a MWCO of $240 \mathrm{Da}$ (NF-TFC, New Logic Research Inc., USA) was also tested. Membranes were kept under distilled water for at least 24 hours prior to separation experiments, which were conducted at $50^{\circ} \mathrm{C}$. Transmembrane pressure (TMP) was set to $0.8 \mathrm{MPa}$ during UF and $3 \mathrm{MPa}$ during NF. A high recirculation flow rate of $16 \mathrm{dm}^{3} / \mathrm{min}$ and a low, $4 \mathrm{dm}^{3} / \mathrm{min} R F R$ s were applied in different experiments. During experiments in vibration mode, the amplitude was set on $2.54 \mathrm{~cm}$ ( 1 inch) by increasing the frequency. Before starting the separation experiments, flux was measured with distilled water, and after the separation experiment was finished, water flux was measured again and compared in order to determine the flux decrease rate. $10 \mathrm{~L}$ of model dairy wastewater was used as feed, and was processed until 2 $\mathrm{L}$ of retentate was left, resulting in a volume reduction ratio (VRR) of 4 , though the dead volume of approximately $1.5 \mathrm{~L}$ of the apparatus needs to be considered, as well as the evaporation which is not negligible in longer experiments.

\subsection{Calculated parameters}

The flux decrease rate, FDR [\%] was calculated by Eq. 1:

$$
\mathrm{FDR}=\left(1-\frac{\mathrm{JWA}_{\mathrm{WA}}}{\mathrm{J}_{\mathrm{WB}}}\right) 100
$$

where $J_{W A}\left[\mathrm{~m}^{3} \mathrm{~m}^{-2} \mathrm{~s}^{-1}\right]$ is the water flux measured - after the separation experiment - on the used, fouled membrane and $J_{W B}\left[\mathrm{~m}^{3} \mathrm{~m}^{-2} \mathrm{~s}^{-1}\right]$ is the water flux measured - before the separation experiment - on the unused, clean membrane. The specific energy demands in non-vibration mode, $S E D_{N V}$ $\left[\mathrm{kWh} \mathrm{m}^{-3}\right]$ and in vibration mode, $S E D_{V}\left[\mathrm{kWh} \mathrm{m}^{-3}\right]$ were defined using the following equations:

$$
\begin{aligned}
& \operatorname{SED}_{\mathrm{NV}}=\frac{\eta_{\mathrm{fp}} \times \mathrm{P}_{\mathrm{fp}}}{\mathrm{J} \times \mathrm{A}_{\text {membrane }}} \\
& \mathrm{SED}_{V}=\frac{\eta_{\mathrm{fp}} \cdot \mathrm{P}_{\mathrm{fp}}+\eta_{V} \cdot \mathrm{P}_{V}}{\mathrm{~J} \times \mathrm{A}_{\text {membrane }}}
\end{aligned}
$$

In non-vibration mode the shear rate, $\gamma\left[\mathrm{s}^{-1}\right]$ was determined with the following Eq. 4 (Delaunay et al., 2008). The maximal shear rate, $\gamma_{w \max }\left[\mathrm{s}^{-1}\right]$ 
and the mean shear rate $\gamma_{w}$ were defined using the Eq. 5 and Eq. 6 (AlAkoum et al., 2002):

$$
\begin{gathered}
\gamma_{\frac{1}{2} \mathrm{~h}}^{\frac{4}{\max }} V_{\max } \\
\gamma_{\mathrm{w} \max }=2^{\frac{1}{2}} \mathrm{~A}(\Pi \mathrm{f})^{\frac{3}{2}} \mathrm{~V}^{-\frac{1}{2}} \\
\gamma_{\mathrm{w}}=\frac{2^{\frac{3}{2}}\left(\mathrm{R}_{2}^{3}-\mathrm{R}_{1}^{3}\right)}{3 \pi \mathrm{R}_{2}\left(\mathrm{R}_{2}^{2}-\mathrm{R}_{1}^{2}\right)} \gamma_{\mathrm{w} \max }
\end{gathered}
$$

where $h$ is the height of the fluid inside the module [m], $v_{\max }$ is the maximal flow velocity inside the module [ $\left.\mathrm{m} \mathrm{s}^{-1}\right], A$ is the amplitude $[\mathrm{m}]$ and $f$ is the frequency $[\mathrm{Hz}]$ of the vibration, $v$ is the dynamic viscosity of the feed $\left[\mathrm{m}^{2} \mathrm{~s}^{-1}\right] . R_{2}$ is the outer radius of the membrane $[\mathrm{m}], R_{1}$ is the inner radius of the membrane $[\mathrm{m}]$.

\section{Results and Discussion}

\subsection{Calculation of shear rates}

By using Eq. 4, 5 and 6 shear rates were calculated in both non-vibration $(N V)$ and vibration $(V)$ mode. Also, Reynolds number $(R e)$ was calculated in $N V$ mode. Re number turned out to be 8494 if the RFR was set to low, and 33975 if it was set to high, meaning that the flow characteristic is laminar in both cases, as the lower limit of transitional flow characteristic is $R e=30000$, as far as liquid films are concerned. The shear rate we have calculated for $N V$ mode was 521 with low, and 2085 with high RFR setting. In $V$ mode, when the amplitude was set to $2.5 \mathrm{~cm}$ (1 inch), the mean shear rate turned out to be 121908, while the maximum shear rate was quite high: 129692.

\subsection{Effect of vibration and RFR on flux, specific energy demand and rejections}

Fluxes of nanofiltration in both $V$ and $N V$ mode, with the RFR set on both high and low are shown in Fig. 1. On the one hand, the highest fluxes can be achieved in vibration mode, but $R F R$ has almost no impact on flux in $V$ mode. On the other hand, the effect of RFR is quite remarkable in NV mode, four times higher $R F R$ results in two times higher flux values. Similar 
experiments were conducted with ultrafiltration, and the results showed a very similar tendency.
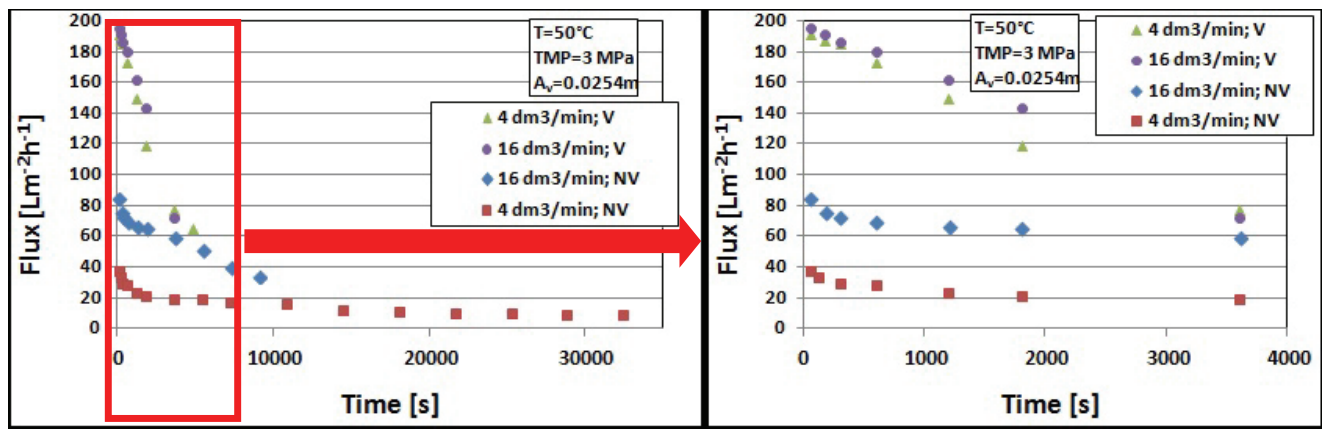

Fig. 1. The impact of vibration and recirculation flow rate on nanofiltration flux values

Specific energy demands of the previously discussed experiments were calculated (Eq. 2 and 3) and are shown in Fig. 2. The conclusion we have reached concerning specific energy demand is the following: In $N V$ mode with low RFR, the process has significantly higher specific energy demands, so we can claim that the effect of $R F R$ is more significant in $N V$ mode. Clearly, in $V$ mode, RFR does not seem to have remarkable influence on energy demands at all. It can be concluded that the vibration had a quite positive effect on the specific energy demands.

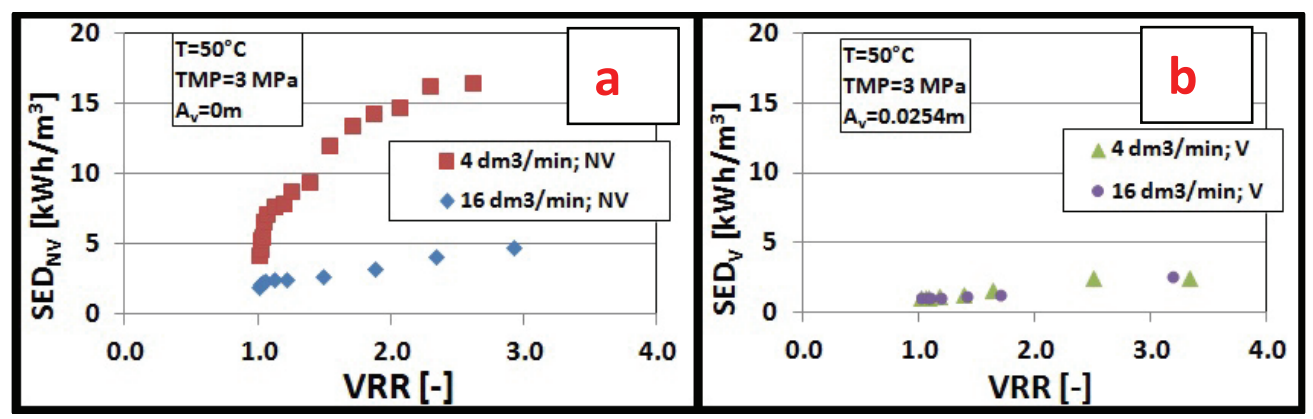

Fig. 2. Specific energy demands (SED) in low and high recirculation flow rate experiments: (a) non-vibration mode $\left(S E D_{N V}\right)$, (b) vibration mode $\left(S E D_{V}\right)$

Chemical oxygen demand (COD) rejections of both UF and NF are shown in Fig. 3. By comparing the COD rejection values calculated in both $V$ and $N V$ mode, and also at high and low RFR, there is no significant 
difference. Though this study focuses on the effects of vibration and $R F R$, it is necessary to keep in mind that the purpose of membrane separation in wastewater treatment is to decrease the pollutants, to meet certain criteria. In Hungary, at present the $28 / 2004 \mathrm{KvVM}$ regulation defines that wastewaters discharged into sewers may have a maximum of $1000 \mathrm{mg} \mathrm{L}^{-1}$ $C O D$, and wastewaters discharged into living waters may not have a $C O D$ value higher than $50-100 \mathrm{mg} \mathrm{L}^{-1}$ (varies by region) (www.kvvm.com, 2016). In our study, processing the model dairy wastewater $\left(C O D=5000 \mathrm{mg} \mathrm{L}^{-1}\right)$ with UF resulted in a permeate with a COD of $\sim 2000 \mathrm{mg} \mathrm{L}^{-1}$, which is significantly higher than the criteria one has to meet to discharge the effluent into sewer. On the other hand, processing it with NF resulted in a permeate with a COD lower than $50 \mathrm{mg} \mathrm{L}^{-1}$, which allows the effluent to be discharged into living waters.
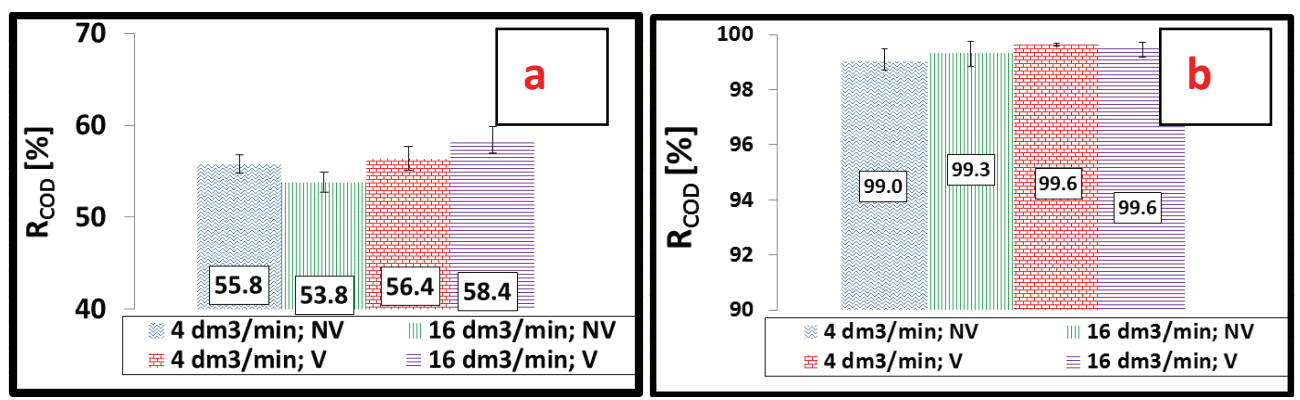

Fig. 3. Chemical oxygen demands rejections of (a) $10 \mathrm{kDa}$ UF membrane and (b) $240 \mathrm{Da}$ NF membrane

Flux decreasing rates $(F D R)$ were calculated by Eq. 1. Regarding both UF and $N F$, increased RFR does not have a significant effect on FDR, neither in $V$ mode nor in $N V$ mode. However, using vibration causes a slight decrease in FDR values, especially in case of NF.

\subsection{Experiments aiming to increase rejection values}

In order to find a way to meet the $1000 \mathrm{mg} \mathrm{L}^{-1} \mathrm{COD}$ threshold criteria of the sewer discharge, another UF membrane with a lower, $7 \mathrm{kDa} M W C O$ was tested. As discussed before, we concluded that the vibration does have a positive overall effect on the process, and the high RFR has some (minor) advantages compared to the low one, in $V$ mode, thus, we have decided to run the following experiments in $V$ mode, with the $R F R$ set to $16 \mathrm{dm}^{3} / \mathrm{min}$. 
Separation tests with the $7 \mathrm{kDa} U F$ membrane were run by the same parameters as the $10 \mathrm{kDa} U F$ tests. COD, electric conductivity and turbidity rejections of the two UF and one $N F$ membranes were measured and are shown in Fig. 4a. Comparing the $10 \mathrm{kDa}$ and the $7 \mathrm{kDa} U F$ rejections shows a significant increase in $C O D$ rejections. There are certain components in milk that have molecular weight $(M W)$ between $10 \mathrm{kDa}$ and $7 \mathrm{kDa}-$ for example glycomacropeptides, with a $M W$ of $8 \mathrm{kDa}$ (Berry et al., 2014), which means that only the $7 \mathrm{kDa} U F$ membrane rejects them. It explains the difference between the COD rejections of the two UF membranes. It was observed that, since our feed model dairy wastewater had a COD of 5000 $\mathrm{mg} \mathrm{L}^{-1}$ and the COD rejection turned out to be higher than $80 \%$ with the 7 $\mathrm{kDa} U F$ membrane, this experiment resulted in a permeate with a COD lower than $1000 \mathrm{mg} \mathrm{L}^{-1}$ - meaning that we have managed to meet the requirements for wastewater discharge into sewers. Fig. $4 a$ also shows a significant, 20\% increase in electric conductivity rejections, when the $10 \mathrm{kDa}$ and $7 \mathrm{kDa} U F$ values are compared. Turbidity rejections were above $99 \%$ in every case. Protein and lactose rejections of the two UF membranes are shown in Fig. 4b. As we could assume based on the COD rejection values, the $7 \mathrm{kDa} U F$ membrane had higher, almost $100 \%$ protein rejection values. It is important to note that the $7 \mathrm{kDa} U F$ lactose rejections are twice as high as the $10 \mathrm{kDa} U F$ rejections.
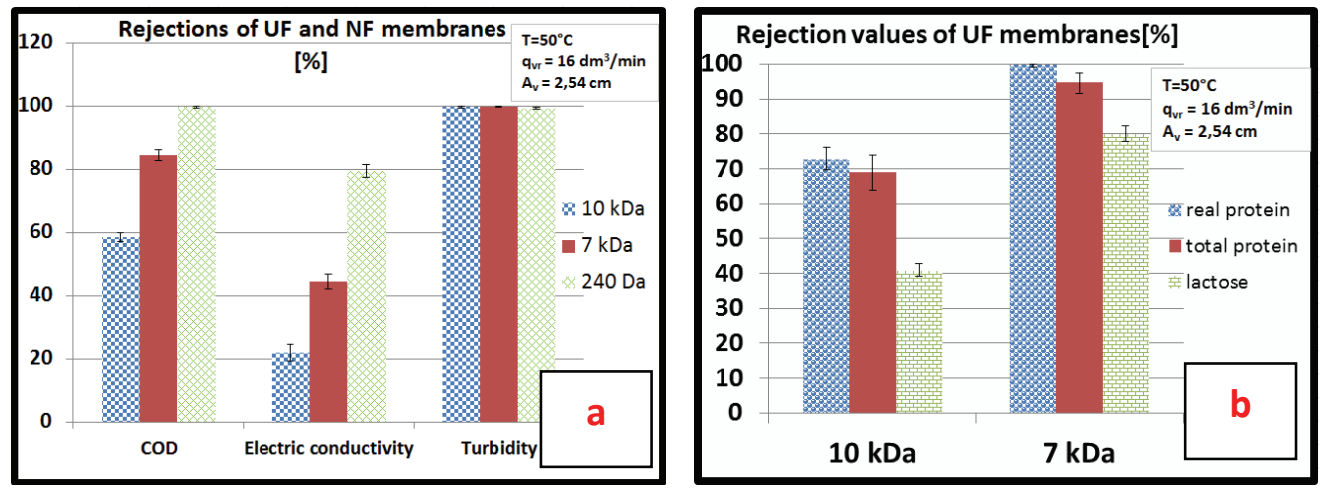

Fig. 4. Rejection values measured calculated for different $U F$ and $N F$ membranes:

(a) COD, EC and turbidity rejections of UF and NF membranes,

(b) protein and lactose rejections of UF membranes

As previously stated, experiments with both UF membranes were carried out with the same parameters. Even if the measured permeate fluxes were similar, the values of specific energy demands showed a noteworthy 
difference: during the experiment with the $10 \mathrm{kDa} U F$ membrane specific energy demand measured at the 30-minute mark was $1.66 \mathrm{kWh} / \mathrm{m}^{3}$, while this value at the same 30 -minute mark turned out to be $2.21-1.66 \mathrm{kWh} / \mathrm{m}^{3}$ when the $7 \mathrm{kDa} U F$ membrane was used, so for the better rejection values we have to invest more energy.

\section{Conclusion}

In this study, UF and NF of the tested dairy model wastewater were investigated. We can conclude that higher shear rate has a positive effect on the process in almost every regard. Increased shear rate resulted in higher flux, higher overall rejection values, as well as a significantly decreased specific energy demand. Furthermore, flux decrease rates became lower. By calculating and comparing the shear rates in experiments with different operating parameters (both vibration and non-vibration mode, low and high recirculation flow rate) we have reached the conclusion that vibration causes a significantly higher shear rate increase than setting the RFR high. This explains another observation we have made, namely, that in nonvibration mode the RFR played a quite important role, the higher RFR resulted in a remarkable positive change in every regard. In vibration mode, the RFR had negligible impact on most investigated aspects, the results were practically the same whether the RFR was set high or low. Also, regarding that the requirements defined by the regulations should be met, we have compared permeate $C O D$ values with the limits set by the law, and concluded that permeate quality of the NF and $7 \mathrm{kDa} U F$ could reach the threshold COD limit, while $10 \mathrm{kDa}$ could not.

\section{Acknowledgments}

Supported by the UNKP-17-4 New National Excellence Program of The Ministry of Human Capacities. Authors are also grateful for the financial support of the Hungarian State and the European Union (EFOP3.6.2-16-2017-00010). Project no. TÉT_16-1-2016-0138 (SRB: 451-0302294/2015-09/4) has been implemented with the support provided from the National Research, Development and Innovation Fund of Hungary, financed under the TÉT_16 funding scheme. 


\section{References}

Al-Akoum, O., Mercier-Bonin, M., Ding, L., Fonade, C., Aptel, P., Jaffrin, M. (2002) Comparison of three different systems used for flux enhancement: application to crossflow filtration of yeast suspensions. Desalination, 147: 31-36.

Berry, S. D., Sheehy, P. A., Williamson, P., Sharp, J. A., Menzies, K., Lefevre, C., Digby, M., Nicholas, K. R., Wynn, P. C., Snell, R. G. (2014) Significance, origin, and function of bovine milk proteins : the biological implications of manipulation or modification. In Singh, Harjinder, Boland, Mike and Thompson, Abby (eds), Milk proteins: from expression to food, Elsevier, Amsterdam, The Netherlands, 113-140.

Bian, R., Yamamoto, K., Watanabe, Y. (2000) The effect of shear rate on controlling the concentration polarization and membrane fouling. Proceedings of the Conference on Membranes in Drinking and Industrial Water Production, 1: 421-432.

Delaunay, D., Rabiller-Baudry, M., Gozálvez-Zafrilla, J. M., Balannec, B., Frappart, M., Paugama, L. (2008) Mapping of protein fouling by FTIR-ATR as experimental tool to study membrane fouling and fluid velocity profile in various geometries and validation by CFD simulation. Chemical Engineering and Processing, 47: 1106-1117.

Frappart, M., Jaffrin, M., Ding, L. H. (2008) Reverse osmosis of diluted skim milk: Comparison of results obtained from vibratory and rotating disk modules. Separation and Purification Technology, 60: 321-329.

Goh, P. S., Lau, W. J., Othman, M. H. D., Ismail, A. F. (2018) Membrane fouling in desalination and its mitigation strategies. Desalination, 425: 130-155.

Jianquan, L., Cao, W., Ding, L. H., Zhu, Z., Wan, Y., Jaffrin, M. Y. (2012) Treatment of dairy effluent by shear-enhanced membrane filtration: The role of foulants. Separation and Purification Technology, 96: 194-203.

Koris, A., Emma, P., Vatai, Gy., Bekassy-Molnar, E., Enrico, D., Lidietta, G. (2011) Investigation on the effects of a mechanical shear-stress modification method during cross-flow membrane emulsification. Journal of Membrane Science, 371: 28-36

Limsawat, P., Pruksasri, S. (2010) Separation of lactose from milk by ultrafiltration. Asian Journal of Food and Agro-Industry, 3(02): 236-243.

Luján-Facundo, M.-J., Mendoza-Roca, J.-A., Cuartas-Uribe, B., Álvarez-Blanco, S. (2017) Membrane fouling in whey processing and subsequent cleaning with ultrasounds for a more sustainable process. Journal of Cleaner Production, 143: 804-813.

Molina, J., Vatai, Gy., Fogarassy, E., Bekassy-Molnar, E. (2008) Application of membrane filtration to wastewater desalination. Progress in Agricultural Engineering Sciences. 4(1): 77-92.

Rezvantalab, S., Bahadori, F. (2015) Natural gas refinery wastewater treatment by zeolites. Progress in Agricultural Engineering Sciences, 11(1): 1-8.

Schroen, K., van Dinther, A., Stockmann, R. (2017) Particle migration in laminar shear fields: A new basis for large scale separation technology? Separation and Purification Technology, 174: 372-388.

Takács, L., Vatai, Gy. (2006) Osmotic pressure modeling of white wine diafiltration and red wine concentration by reverse osmosis. Progress in Agricultural Engineering Sciences, 2(1): 119-132. 
Zhenzhou, Z., Houcine, M., Wenxiang, Z., Luhui, D., Olivier, B., Michel, Y. J., Nabil, G., Eugène, V. (2016) Rotating disk-assisted cross-flow ultrafiltration of sugar beet juice. Food Bioprocess Technology, 9: 493-500.

www.kvvm.hu/szakmai/karmentes/kiadvanyok/karmkezikk2/2-14.htm; 2016.10.11 